\title{
A New Two-Step Method for Synthesis of Polycarbonates
}

\author{
Gabriel RoKICKI, Barbara POGORZELSKA-MARCINIAK, \\ and Witold KURAN \\ Institute of Organic Chemistry and Technology, Technical University, \\ Politechnika, Koszykowa 75, 00-662 Warsaw, Poland
}

(Received March 31, 1982)

\begin{abstract}
Carbonate monomers, such as 1,4-bis(cyclohexyloxycarbonyloxylmethyl)benzene and related compounds were synthesized from potassium cyclohexanolate, $\mathrm{CO}_{2}$, and $\alpha, \omega$-dibromo compounds in the presence of 18-crown-6 ether in aprotic solvents. Poly $(p$ xylylidene) was found to be formed in addition to the carbonate monomer when all the substances were simultaneously introduced into the reaction mixture. By an appropriate reaction method and conditions the formation of by-products was eliminated, thus permitting the main product 1,4bis(cyclohexyloxycarbonyloxymethyl)benzene to be obtained in a yield higher than $90 \%$ with respect to the $p$-xylylene $\alpha, \omega$-dibromide introduced. The carbonate monomer thus obtained was then used in transesterification with diols or diphenols, and also in an ester exchange reaction to form the corresponding polycarbonates. The polycarbonates obtained were characterized and their reduced viscosity was determined.
\end{abstract}

KEY WORDS Carbon Dioxide / Crown Ether / 1,4-Bis(cyclohexyloxycarbonyloxymethyl)benzene / Transesterification / Polycarbonate /

Aliphatic-aromatic polycarbonates are obtained from transesterification of alkyl or aryl carbonates with dihydroxy compounds or by ester exchange reaction of dihydroxy compounds with alkyl or aryl carbonates. The formation of aliphatic-aromatic polycarbonates by ester exchange of the alkyl or aryl carbonates of dihydroxy compounds, e.g. pxylylene glycol, is widely reported in the literature, especially in patents. Alkyl or aryl carbonates of diols were obtained hitherto from the reaction of the corresponding dichloroformates with an excess of alcohols or phenols, or from alkyl or aryl chloroformates with dihydroxy compounds. All the methods mentioned above require application of phosgene, a highly toxic gas in different reaction stages.

Recently Soga et al. ${ }^{1}$ proposed the direct application of neutral and easily available carbon dioxide in the preparation of polycarbonates by the polycondensation* expressed by eq 1 .

$$
\begin{aligned}
& n \mathrm{KO}-\mathrm{H}-\mathrm{OK}+2{ }_{n} \mathrm{CO}_{2}+n \mathrm{BrCH}_{2} \longrightarrow \mathrm{CH}_{2} \mathrm{Br} \stackrel{18-\text { Crown-6 }}{\longrightarrow} \\
& {\left[\mathrm{H}-\mathrm{OCO}-\mathrm{CH}_{2}-\bigcirc-\mathrm{CH}_{2}-\mathrm{OCO}\right.}
\end{aligned}
$$

Polymers of molecular weight not exceeding $4,000-6,000$ are obtained in low yield by the above process.
In order to eliminate the inconvenience, a two step process for the preparation of aliphaticaromatic polycarbonates using gaseous carbon di-

* The direct application of $\mathrm{CO}_{2}$ for the preparation of aliphatic polycarbonates in the addition polymerization was proposed earlier by Inoue et al. ${ }^{2}$ Reviews covering both the addition polymerization and polycondensation reaction by the direct use of $\mathrm{CO}_{2}$ have been published elsewhere. ${ }^{3}$ 
oxide is proposed. In the first step 1,4-bis(cyclohexyloxycarbonyloxymethyl)benzene is obtained from the reaction of cyclohexanol, $\mathrm{CO}_{2}$, and $p$-xylylene dibromide in the presence of 18 crown-6 ether as an activating agent (eq 2).

$$
\begin{aligned}
& 2\left\langle\mathrm{H}-\mathrm{OK}+2 \mathrm{CO}_{2}+\mathrm{BrCH}_{2}-\mathrm{O}-\mathrm{CH}_{2} \mathrm{Br} \stackrel{18-\text { Crown-6 }}{\longrightarrow}\right. \\
& \mathrm{H}-\mathrm{OCO}-\mathrm{CH}_{2}-\mathrm{O}-\mathrm{CH}_{2}-\mathrm{OCO}-\mathrm{H}+2 \mathrm{KBr}
\end{aligned}
$$

The carbonate monomer then undergoes transesterification with dihydroxy compounds (eq 3) or an ester exchange reaction (eq 4), resulting in the formation of the respective polycarbonates.

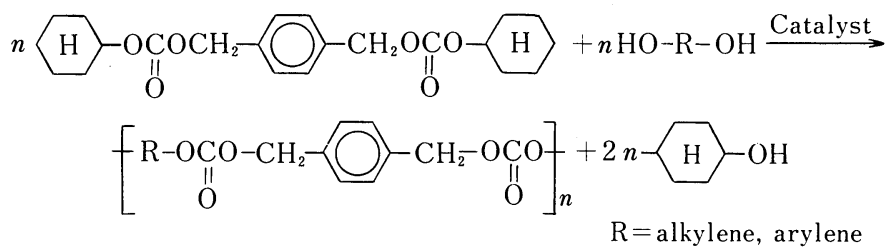<smiles>O=C(OCc1ccc(CO[Ge](=O)OC2CCCCC2)cc1)OC1CCCCC1</smiles>

In the present work, the formation process of 1,4bis(cyclohexyloxycarbonyloxymethyl)benzene and related carbonate monomers $\left[4,4^{\prime}\right.$-bis(cyclohexyloxycarbonyloxymethyl)diphenylmethane and $4,4^{\prime}$ bis(cyclohexyloxycarbonyloxymethyl)biphenyl] and the possibility of using them for the synthesis of polycarbonates have been studied.

\section{EXPERIMENTAL}

\section{Materials}

4-Bromomethyl benzyl bromide was obtained from the reaction of $p$-xylylene glycol with hydrogen bromide and was purified by crystallization from carbon tetrachloride. ${ }^{4}$ 4,4'-Bis(bromomethyl)diphenylmethane and 4,4'-bis(bromomethyl)biphenyl were obtained from the reaction of diphenylmethane and biphenyl, respectively, with paraformaldehyde in the presence of gaseous hydrogen bromide. ${ }^{5,6}$ 1,4-Cyclohexanediol, $p$-xylylene glycol, 2,2-bis(4-hydroxyphenyl)propane (bisphenol A), and 2,2-bis(4-hydroxycyclohexyl)propane (hydrogenated bisphenol A) were purified by crystallization from methanol or chlorobenzene.

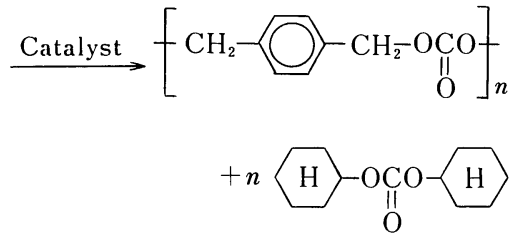

The solvents were purified according to commonly known methods. 18 -Crown-6 ether $(1,4,7,10,13$, 16-hexaoxacyclooctadecane) was obtained according to the method described in the literature. $^{7}$ Potassium cyclohexanolate was obtained according to the following procedure. Under a nitrogen atmosphere $34.85 \mathrm{~g}(0.3 \mathrm{~mol})$ of cyclohexanol was added to a mixture of $120 \mathrm{~cm}^{3} \mathrm{THF}$ and $11.73 \mathrm{~g}(0.3 \mathrm{~mol})$ of potassium. The mixture was maintained at the boiling point until the potassium had completely reacted for $c a .52 \mathrm{~h}$. During the reaction, a white crystalline salt precipitated which was filtered off under nitrogen. It was washed with $40 \mathrm{~cm}^{3}$ of THF and $20 \mathrm{~cm}^{3}$ of dry diethyl ether and then dried at room temperature under reduced pressure. Potassium cyclohexanolate was also obtained but by a different procedure. Under a nitrogen atmosphere, $16.83 \mathrm{~g}(0.3 \mathrm{~mol})$ of granulated potassium hydroxide was added to $34.85 \mathrm{~g}(0.3 \mathrm{~mol})$ of cyclohexanol and the vigorously stirred mixture was heated for $c a .0 .5 \mathrm{~h} .130 \mathrm{~cm}^{3}$ of benzene was then added and water was azeotropically distilled off the mixture. The reaction was carried out for $c a .32 \mathrm{~h}$ under a nitrogen atmo- 
sphere. Potassium cyclohexanolate was filtered off and washed with $30 \mathrm{~cm}^{3}$ of THF and $20 \mathrm{~cm}^{3}$ of diethyl ether.

\section{Preparation of Carbonate Monomers}

Method I. In a $50 \mathrm{~cm}^{3}$ pressure autoclave $1.38 \mathrm{~g}$ $(10 \mathrm{mmol})$ of potassium cyclohexanolate, $0.3 \mathrm{~g}(1.1$ $\mathrm{mmol})$ of 18 -crown-6 ether, $0.67 \mathrm{~g}(2.5 \mathrm{mmol})$ of 4 bromomethyl benzyl bromide (or the corresponding amount of another dibromo derivative for other carbonate monomers) and $10 \mathrm{~cm}^{3}$ of a solvent were added under nitrogen. Gaseous carbon dioxide was then introduced to the system under a pressure of 30 atm during 20 minutes. The autoclave was then placed in a thermostated oil bath at $80^{\circ} \mathrm{C}$ for $48 \mathrm{~h}$. After completion of the reaction, $\mathrm{CO}_{2}$ was released from the autoclave and the reaction product, depending on the solvent used, was filtered off from the $\mathrm{KBr}$ formed, washed with water (in the case of benzene solvent) and after evaporating part of the solvent, was crystallized. When using dioxane, diglyme and acetonitrile as solvent, after filtering off $\mathrm{KBr} 25 \mathrm{~cm}^{3}$ of water was added to the filtrate. A white crystalline precipitate of the carbonate monomer was isolated, and was washed with a large amount of water.

Method II. In this method, $\mathrm{CO}_{2}$ is introduced to the autoclave before adding the dibromo derivative. After 15 minutes, $\mathrm{CO}_{2}$ was released from the autoclave and the dibromo derivative was added. The introduction of $\mathrm{CO}_{2}$ under pressure for 15 minutes was repeated. From now the procedure is as in method I. A modification of this method was the introduction to the autoclave, besides potassium cyclohexanolate, crown ether and solvent, of the bromo derivative placed in a closed glass ampoule. This ampoule was broken 15-20 minutes after joining the autoclave with the $\mathrm{CO}_{2}$ gas cylinder. Further procedure was carried out as in Method I.

\section{Polycondensation}

Transesterification with Diols. In a $50 \mathrm{~cm}^{3}$ glass reaction flask equipped with a stirrer, $19.53 \mathrm{~g}(0.05$ mol) of 1,4-bis(cyclohexyloxycarbonyloxymethyl)benzene, $0.05 \mathrm{~mol}$ of a dihydroxy compound and a catalyst $(2 \mathrm{wt} \%)$ were placed under nitrogen. The reaction flask was placed in an oil bath and the contents heated at $160^{\circ} \mathrm{C}$ for 30 minutes. Cyclohexanol formed as a by-product was distilled off under reduced pressure with a water pump first and then at $240-245^{\circ} \mathrm{C}$ for $1.5 \mathrm{~h}$ with an oil pump ( 1 Torr). At the end of the reaction, the polymer became viscous, forming a thick mass.

Ester Exchange. In a $50 \mathrm{~cm}^{3}$ glass reaction flask equipped with a stirrer, $39.05 \mathrm{~g}(0,1 \mathrm{~mol}), 1,4-$ bis(cyclohexyloxycarbonyloxymethyl)benzene and $2 \mathrm{wt} \%$ of the catalyst $-\mathrm{Ti}(\mathrm{OBu})_{4}$ were heated at $180^{\circ} \mathrm{C}$ for $0.5 \mathrm{~h}$ and then at $240^{\circ} \mathrm{C}$ for $2 \mathrm{~h}$. The reaction was carried out under reduced pressure (1 Torr, oil pump). A yellowish product was obtained.

\section{Product Analysis}

IR spectra were recorded on a Perkin-Elmer 521 spectrophotometer. ${ }^{1} \mathrm{H}$ NMR spectra were recorded on a $100 \mathrm{MHz}$ JEOL NMR spectrometer using TMS as an internal standard. Elemental analysis was carried out by a Perkin-Elmer 240 apparatus. Viscosity was determined using a Ubbelohde viscometer at $25^{\circ} \mathrm{C}$ with $\mathrm{CHCl}_{3}$ as the solvent.

\section{RESULTS AND DISCUSSION}

The reaction of potassium cyclohexanolate, $\mathrm{CO}_{2}$, and (4-bromomethyl)benzyl bromide was first carried out in dioxane according to method I, when simultaneously introducing all the reactants, consisted of a yellow precipitate insoluble in dioxane and of a white-yellow crystalline precipitate isolated from the dioxane solution by addition of water.

Elemental analysis and IR and ${ }^{1} \mathrm{H}$ NMR spectra confirmed the fraction soluble in dioxane confirmed the structure of 1,4-bis(cyclohexyloxycarbonyloxymethyl)benzene (Figures 1, 2 and Table I). In the IR spectrum, strong absorption bands at 1740 and $1240-1270 \mathrm{~cm}^{-1}$, corresponding to the stretching vibrations of carbonyl groups and $\mathrm{C}-\mathrm{O}$ bonds of linear carbonates, were observed. In the ${ }^{1} \mathrm{H}$ NMR spectrum, the following signals were present: aromatic protons $(\delta=7.5 \mathrm{ppm})$, methylene protons neighboring with the carbonate linkage $(\delta=4.9 \mathrm{ppm}(\mathrm{s}))$, methine protons of the cyclohexanol ring $(\delta=4.45 \mathrm{ppm}(\mathrm{m}))$, and methylene protons of the cyclohexanol ring $(\delta=$ $1.5 \mathrm{ppm}(\mathrm{m}))$ of intensity ratio $2: 2: 1: 10$.

The yellow precipitate with a melting point above $400^{\circ} \mathrm{C}$ insoluble in dioxane, did not disolve in any available solvent even in boiling DMSO and $\mathrm{CF}_{3} \mathrm{COOH}$. In the IR spectrum of the precipitate, strong absorption bands at 1742 and 1240-1270 


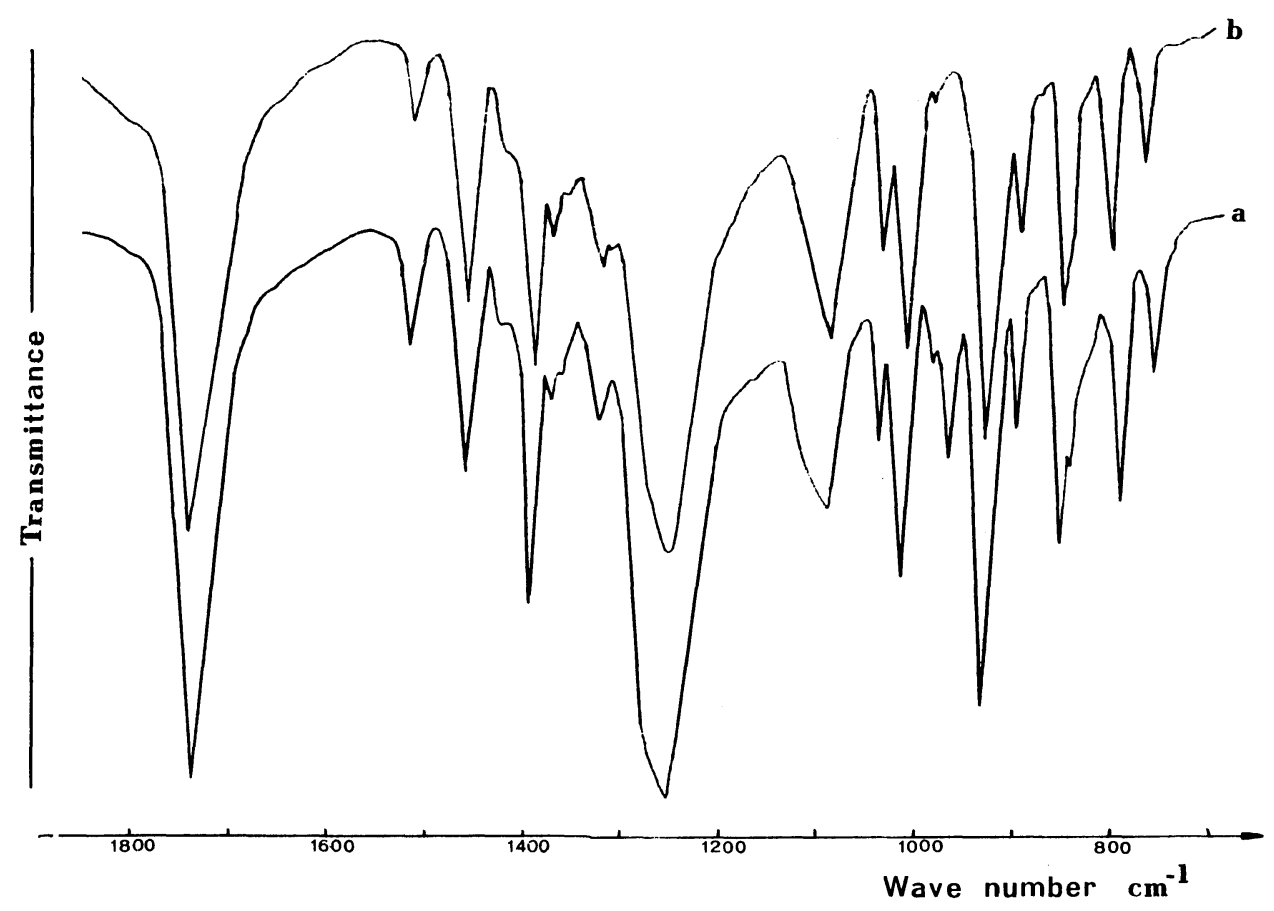

Figure 1. IR spectra of reaction products obtained from potassium cyclohexanolate, $\mathrm{CO}_{2}$ and 4bromomethylbenzyl bromide in dioxane as the reaction medium according to method I: a) fraction insoluble in dioxane-poly(p-xylylidene); b) fraction soluble in dioxane-1,4-bis(hexyloxycarbonyloxymethyl)benzene; reaction conditions as in Table I.

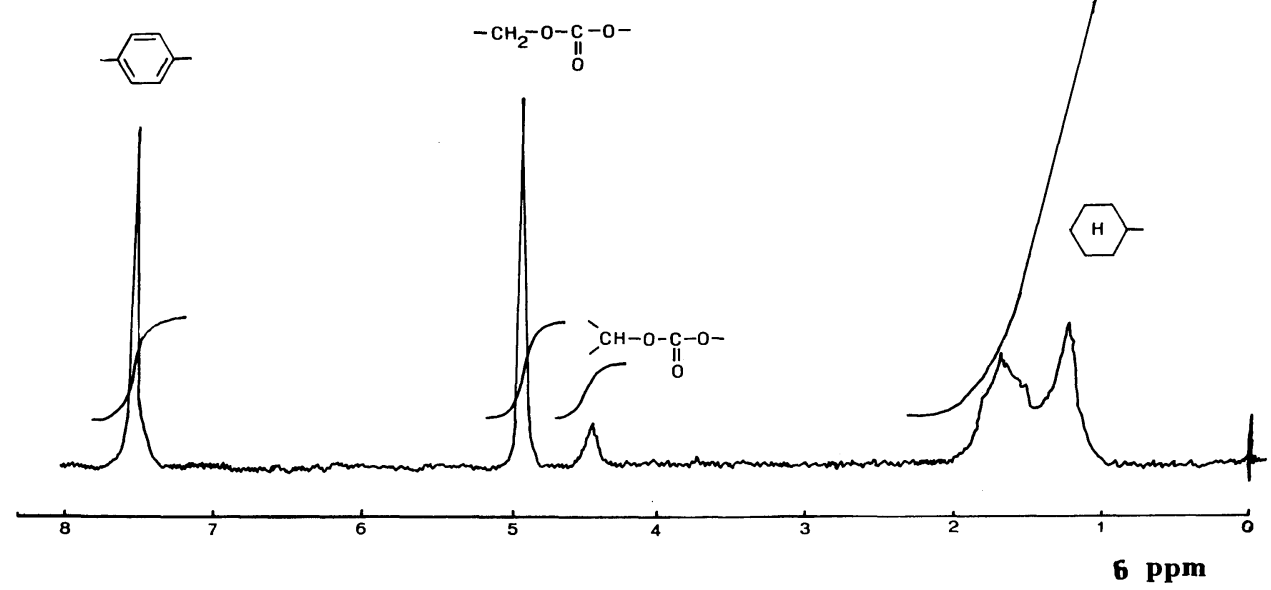

Figure 2. ${ }^{1} \mathrm{H}$ NMR spectrum of 1,4-bis(cyclohexyloxycarbonyloxymethyl)benzene in $\mathrm{CDCl}_{3}$. 
Table I. Effect of solvent type on the yield of 1,4-bis(cyclohexyloxycarbonyloxymethyl)benzene in the reaction of H $-\mathrm{OK}, \mathrm{CO}_{2}$ and

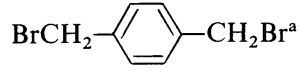

\begin{tabular}{|c|c|c|c|c|}
\hline \multirow[b]{2}{*}{ No. } & \multirow[b]{2}{*}{ Solvent } & \multicolumn{2}{|c|}{ Yield/g $(\%)$} & \multirow[b]{2}{*}{$\begin{array}{l}\text { Preparation } \\
\text { method }^{\mathrm{d}}\end{array}$} \\
\hline & & $\begin{array}{l}\text { Soluble } \\
\text { fraction }^{b}\end{array}$ & $\begin{array}{l}\text { Insoluble } \\
\text { fraction }^{c}\end{array}$ & \\
\hline 1 & Dioxane & $0.35(36)$ & $0.30(31)$ & I \\
\hline 2 & Dioxane & $0.90(91)$ & $-\quad-$ & II \\
\hline 3 & Benzene & - & $0.60(62)$ & I \\
\hline 4 & Benzene & $0.91(92)$ & -- & II \\
\hline 5 & Acetonitrile & $0.30(31)$ & $0.20(21)$ & I \\
\hline 6 & Acetonitrile & $0.50(52)$ & -- & II \\
\hline 7 & THF & $0.43(46)$ & $-\quad-$ & II \\
\hline 8 & Diglyme & $0.25(28)$ & $-\quad-$ & II \\
\hline \multicolumn{5}{|c|}{$\begin{array}{l}\text { a Reaction conditions: }\langle\mathrm{H}-\mathrm{OK}, 1.38 \mathrm{~g}(10 \mathrm{mmol}) ; \\
\mathrm{BrCH}_{2}-\mathrm{CH}_{2} \mathrm{Br}, 0.67 \mathrm{~g}(2.5 \mathrm{mmol}) ; \mathrm{CO}_{2} \\
\text { pressure, } 30 \mathrm{~atm} ; 18 \text {-crown-6 ether, } 0.3 \mathrm{~g}(1.1 \mathrm{mmol}) ; \\
\text { solvent, } 10 \mathrm{~cm}^{3} ; \text { temp, } 80^{\circ} \mathrm{C} \text {; time, } 48 \mathrm{~h} . \\
\text { b } 1,4-\mathrm{Bis}(\text { cyclohexyloxycarbonyloxymethyl }) \text { benzene. } \\
\text { c Poly }(p \text {-xylylidene). } \\
\text { d See ExPERIMENTAL part. }\end{array}$} \\
\hline
\end{tabular}

$\mathrm{cm}^{-1}$, corresponding to the stretching vibrations of linear carbonate bonds, and an absorption band at $960 \mathrm{~cm}^{-1}$, characteristic for trans-vinylene linkages, were present (Figure 1). The results obtained indicate that in the case of Method I, where the reactants are introduced simultaneously to the reaction flask, besides the expected reaction leading to the formation of 1,4-bis(cyclohexyloxycarbonyloxymethyl)benzene but also a side reaction leading to the formation of $\operatorname{poly}(p$-xylylidene $)$ takes place. This is indicated by the melting point above $400^{\circ} \mathrm{C}$, insolubility in boiling aggressive solvents and the yellow color, caused by the presence of a conjugated double bond system. The reaction of potassium cyclohexanolate, $\mathrm{CO}_{2}$, and (4-bromomethylbenzyl) bromide carried out according to Method $\mathrm{I}$ in acetonitrile as the reaction medium led to the formation, similarly as in dioxane, of both 1,4-bis(cyclohexyloxycarbonyloxymethyl)benzene and poly( $p$-xylylidene). However, when carried out in benzene, it led to the formation of only the latter polymer in a considerably high yield (Table I). The reaction, in which poly ( $p$-xylylidene) is formed probably proceeds according to the mechanism expressed schematically by eq 5 .

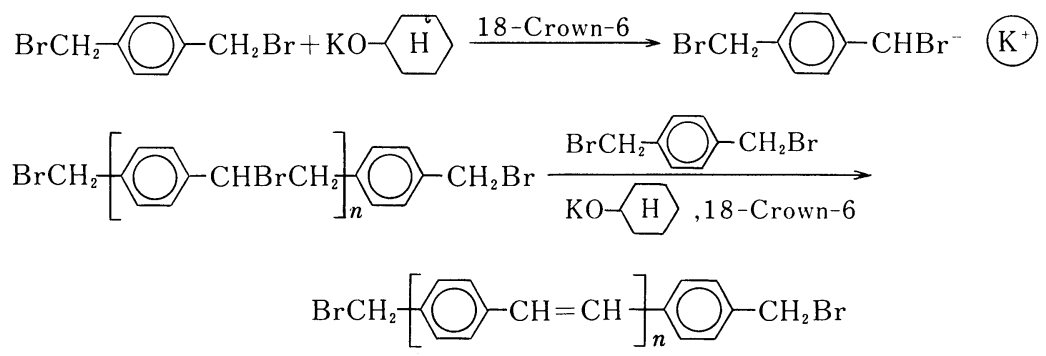

The presence in the reaction system of a strong nucleophile, which the cyclohexanolate anion due to the introduction of a crown ether complexing the potassium cation, causes the abstraction of a methylene proton, instead of a bromide anion, and then the formation of a thermodynamically stable poly ( $p$-xylylidene) system. The rate of this reaction is great, which is indicated by the relatively high yield of the side product.

The presence of absorption bands at 1742 and $1240-1270 \mathrm{~cm}^{-1}$ characteristic of carbonate lin- kages, besides a band at $960 \mathrm{~cm}^{-1}$, indicates the incorporation of $\mathrm{CO}_{2}$ to the poly( $p$-xylylidene) chain, probably at the ends of its molecules (eq 6).

Elemental analysis gave the following results $\left(\mathrm{wt}^{\mathrm{o}} \%\right.$ ): C, 72.9\%; H, 6.8\%; Br, 5.0\%; C: $\mathrm{H}=10.7$. (Calcd for I $(n=2): \mathrm{C}, 76.7 \% ; \mathrm{H}, 7.1 \% ; \mathrm{C}: \mathrm{H}=$ 10.8). The bromine content is thought to be due to incomplete dehydrobromination. 


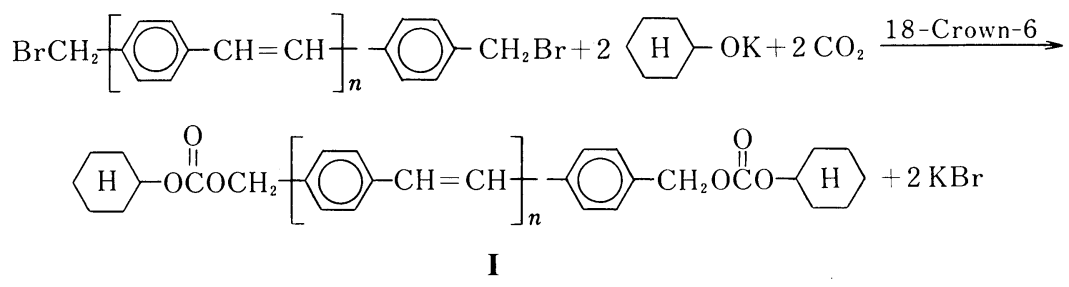

On the basis of the work of Cambell and McDonald, ${ }^{8}$ the $n$ value for poly ( $p$-xylylidene) does not exceed 10 , hence the intensity of absorption bands of carbonate linkages is relatively great. When using 4,4'-bis(bromomethyl)diphenylmethane for the reaction, the product obtained according to Method I was viscid and insoluble in the solvents available.

The reaction product of potassium cyclohexanolate, $\mathrm{CO}_{2}$ and 4,4'-bis(bromomethyl)biphenyl (obtained according to Method I) did not contain an insoluble yellow fraction. The IR spectrum of the crystalline precipitate showed the presence of linear carbonate linkages (absorption bands at 1740 and $1250-1270 \mathrm{~cm}^{-1}$ ) and ether bonds (absorption band at $1085 \mathrm{~cm}^{-1}$ of $\mathrm{C}-\mathrm{O}-\mathrm{C}$ stretching vibrations). The ${ }^{1} \mathrm{H}$ NMR spectrum contained signals of aromatic protons $(\delta=7.3 \mathrm{ppm})$, methylene protons neighboring with carbonate linkages $(\delta=5.0$ ppm (s)), cyclohexanol methine protons $(\delta=4.6$ ppm (m)), methylene protons neighboring with ether bonds $(\delta=4.35 \mathrm{ppm}(\mathrm{s}))$ and cyclohexanol methylene protons in the region $\delta=1-2 \mathrm{ppm}(\mathrm{m})$ of intensity ratio, $4: 1.4: 1: 0.6: 10$. The above results indicate that the reaction product contains ca. $30 \%$ of ether bonds, indicating the incomplete incorporation of $\mathrm{CO}_{2}$ to the product formed according to eq 2 . Other data concerning the reaction products obtained according to Methods I and II are summarized in Tables I and II.

To avoid any side reactions leading to the formation of $p$-xylylidene chains and ether bonds as well the reaction procedure was changed. The cyclohexyl potassium carbonate was first obtained (bromo derivative placed in a closed ampoule and isolated from the reaction medium), which was then treated with the bromo derivative (by breaking the ampoule). The alkylpotassium carbonate is a stable salt since the decarboxylation would have to produce alkoholate anions of lower stability than that of $\mathrm{ROCOO}^{-}$. The cyclohexylcarbonate anion is considerably less nucleophilic and reaction (5) with the abstraction of the methylene proton, does not take prace. As the IR and ${ }^{1} \mathrm{H}$ NMR spectral analyses showed, the products of the reaction carried out according to Method II did not contain $p$ -

Table II. Carbonate monomers $\mathrm{H}-\underset{\mathrm{O}}{\mathrm{O}} \mathrm{OCCH}_{2} \mathrm{RCH}_{2} \mathrm{OCO}-\mathrm{H}$ obtained from the reaction of $\left\langle\mathrm{H}-\mathrm{OK}, \mathrm{CO}_{2}\right.$, and dibromo derivatives $\mathrm{BrCH}_{2} \mathrm{RCH}_{2} \mathrm{Br}^{\mathrm{a}}$

\begin{tabular}{|c|c|c|c|c|c|c|}
\hline \multirow{2}{*}{$\mathrm{R}$} & \multicolumn{3}{|c|}{ Elemental analysis $/ \%$} & \multirow{2}{*}{$\frac{\mathrm{mp}}{{ }^{\circ} \mathrm{C}}$} & \multirow{2}{*}{$\frac{\text { Yield }}{\%}$} & \multirow{2}{*}{$\begin{array}{c}\text { Preparation } \\
\text { method }\end{array}$} \\
\hline & & $\mathrm{C}$ & $\mathrm{H}$ & & & \\
\hline & Found & 67.21 & 7.62 & \multirow{2}{*}{$110-112$} & 36 & I \\
\hline & Calcd & 67.66 & 7.76 & & 91 & II \\
\hline & Found & 71.84 & 7.25 & \multirow{2}{*}{$104-108$} & 34.5 & I \\
\hline & Calcd & 72.06 & 7.36 & & 62.7 & II \\
\hline & & - & - & $52-55$ & - & $\begin{array}{r}\text { I } \\
\text { II }\end{array}$ \\
\hline
\end{tabular}

a Reaction conditions are the same as in Table I.

b See EXPERIMENTAL part. 
Table III. Characterization of polycarbonates obtained from the transestrification of 1,4-bis(cyclohexyloxycarbonyloxymethyl)benzene with dihydroxy compounds and from ester exchange ${ }^{\mathrm{a}}$

\begin{tabular}{|c|c|c|c|c|}
\hline \multirow{2}{*}{ No. } & \multirow{2}{*}{ Dihydroxy compound } & \multirow{2}{*}{ Catalyst } & $\begin{array}{c}\text { Softening } \\
\text { point }\end{array}$ & \multirow{2}{*}{$\frac{\eta_{\text {red }}}{\mathrm{dl} \mathrm{g}^{-1}}$} \\
\hline & & & ${ }^{\circ} \mathrm{C}$ & \\
\hline 1 & 1,4-Cyclohexanediol & $\mathrm{Ti}(\mathrm{OBu})_{4}$ & $105-116$ & 0.6 \\
\hline 2 & 1,4-Cyclohexanediol & $\mathrm{Ti}(\mathrm{Oi}-\mathrm{Pr})_{4}$ & $90-96$ & 0.5 \\
\hline 3 & Bisphenol A & $\mathrm{Ti}(\mathrm{OBu})_{4}$ & - & 0.3 \\
\hline 4 & Hydrogenated bisphenol A & $\mathrm{Ti}(\mathrm{OBu})_{4}$ & $173-178$ & $-^{\mathrm{b}}$ \\
\hline
\end{tabular}

a Reaction conditions: see EXPERIMENTAL part.

b Insoluble polymer.

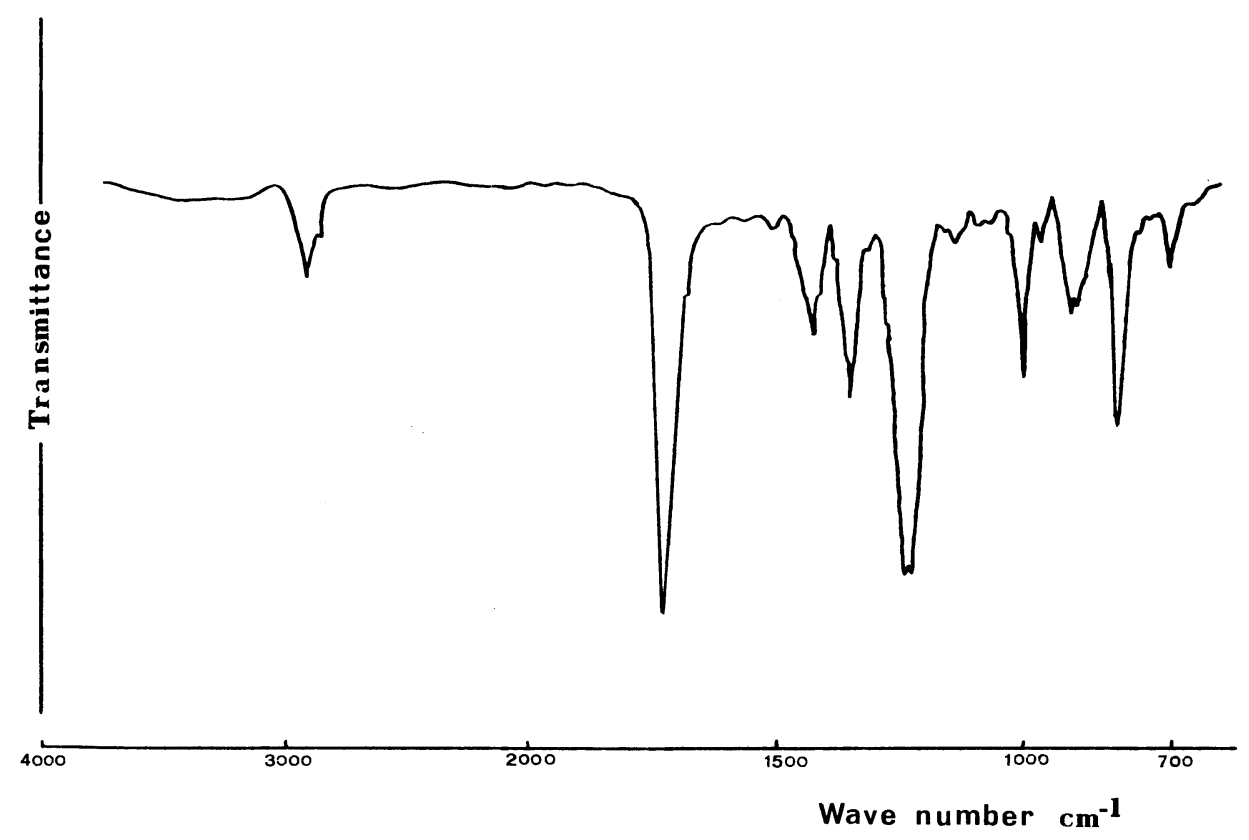

Figure 3. IR spectrum of polycarbonate oxymethyl)benzene and 1,4-cyclohexane diol.

xylylidene and ether linkages. Tables I and II contain the yields and basic physico-chemical data on carbonate monomers.

The method presented allows to quantitatively isolate carbonate monomers and purify them by crystallization and then use them for the preparation of aliphatic-aromatic polycarbonates by transesterification with diols (eq 3 ) or by ester exchange in block (eq 4).

Table III contains basic data on polycarbonates obtained from 1,4-bis(cyclohexyloxycarbonyl-

obtained from different diols using titanium catalysts. The IR and ${ }^{1} \mathrm{H}$ NMR spectra of polycarbonate obtained from 1,4-bis(cyclohexyloxycarbonyloxymethyl) benzene and 1,4-cyclohexanediol are analogous to those of the polycarbonate obtained from the cyclohexanediol dipotassium salt, $\mathrm{CO}_{2}$, and 4-bromomethylbenzyl bromide. ${ }^{1}$ However, the IR spectrum (Figure 3) of the polycarbonate obtained by the transesterification did not contain an absorption band at $760 \mathrm{~cm}^{-1}$ 
characteristic for carbon-bromine bonds in bromomethyl groups occurring as end groups of the polymer obtained by direct method. ${ }^{1}$

The ester exchange of 1,4-bis(cyclohexyloxycarbonyloxymethyl)benzene was found to produce, according to eq 6 , a polymer of molecular weight ca. 18,000 of a structure analogous to that of the polycarbonate obtained in the polycondensation of potassium carbonate and (4-bromomethyl)benzyl bromide. ${ }^{9}$ The method described here also permits the preparation of a polymer from bisphenol A. The IR and NMR spectra of the polymer are analogous to those of the polycarbonate obtained from the bisphenol $\mathrm{A}$ potassium salt, $\mathrm{CO}_{2}$, and (4-bromomethylbenzyl) bromide. ${ }^{1,10}$

The results from this work indicate that the overall yield of the polycarbonate synthesis by the two-step process, including the formation of the monomer and its transesterification or ester exchange, is much higher than that by the direct method. Besides, higher molecular weight polymers are obtained, which indicate the reduced viscosity values of the polycarbonates.

Acknowledgement. This work was financed by the Polish Academy of Science (Grant MR I-31).

\section{REFERENCES}

1. K. Soga, Y. Toshida, S. Hosoda, and S. Ikeda, Makromol. Chem., 178, 2747 (1977); ibid., 179, 2379 (1978).

2. S. Inoue, H. Koinuma, and T. Tsuruta, J. Polym. Sci., Polym. Lett. Ed., 7, 287 (1969); Makromol. Chem., 130, 210 (1969).

3. a. A. Rokicki and W. Kuran, J. Macromol. Sci. Rev. Macromol. Chem., C21, 135 (1981).

b. N. Yamazaki, F. Higashi, and S. Inoue, "Organic and Bioorganic Chemistry of Carbon Dioxide," S. Inoue and N. Yamazaki, Ed., Kodansha Ltd., Tokyo, 1981.

4. D. Kamm and C. S. Marvel, Org. Synth. Coll., 1, 29 (1941).

5. J. A. Goodson, Br. J. Pharmacol., 3, 49 (1948).

6. M. Tomita and K. Takahashi, J. Pharm. Soc. Jpn., 73, 760 (1953).

7. G. Gokel and D. Cram, J. Org. Chem., 39, 1070 (1974).

8. R. N. McDonald and T. W. Campbell, J. Am. Chem. Soc., 82, 4669 (1960).

9. K. Soga, S. Hosoda, and S. Ikeda, J. Polym. Sci., Polym. Chem. Ed., 17, 517 (1979); K. Soga, S. Hosoda, and S. Ikeda, J. Polym. Sci., Polym. Lett. Ed., 15, 611 (1977).

10. G. Rokicki, W. Kuran, and J. Kiełkiewicz, J. Polym. Sci., Polym. Chem. Ed., 20, 967 (1982). 